\title{
ON THE RELATION BETWEEN SEA SURFACE AND LOWER TROPOSPHERE TEMPERATURE OVER THE NORTHERN HEMISPHERE
}

\section{A. BARTZOKAS ${ }^{1, *}$ \\ D. A. METAXAS ${ }^{1}$ \\ B. D. GILES ${ }^{2}$}

\author{
${ }^{1}$ Laboratory of Meteorology \\ Department of Physics \\ University of loannina \\ 45110 loannina, Greece \\ ${ }^{2}$ Department of Meteorology \\ School of Geography \\ The University of Birmingham \\ B15 2Tा Birmingham, United Kingdom
}

*to whom all correspondence should be addressed

tel: $+30-26510-98477$

fax: +30-26510-98699

Received: $14 / 03 / 03$

Accepted: 07/07/03 e-mail: abartzok@cc.uoi.gr http://www.physics.uoi.gr/seci/aris.html

\begin{abstract}
In this work the covariability of sea surface and lower troposphere temperatures (SST-AT) is investigated for winter (DJFM) and summer (JJAS), over the whole northern hemisphere, by utilizing monthly anomalies in grid boxes for a 22-year period. Air temperature variations in the lower troposphere are examined in terms of 1000-500 hPa thickness. At first, factor analysis (FA) is applied on both sets of data in order to reduce their dimensionality and to group objectively grid points with a similar long term temperature variability. Also, FA revealed numerous teleconnections in both fields, most important being those governed by PNA in the Pacific Ocean and NAO in the Atlantic Ocean. Then, by using the FA results as a guide, correlation coefficients between the mean temperature time series of the subareas defined by FA in the two fields are estimated. The highest values, up to $r=0.70$, were found for subareas located one over/under the other. Finally, by introducing time lags, an attempt of forecasting either SST form AT or AT from SST is made. Although in some cases the coefficients appear increasing, test showed that the increase is not statistically significant. In any case, it appears that, on monthly time scale, it is the AT that controls SST and not the vice versa.
\end{abstract}

KEYWORDS: northern hemisphere, factor analysis, sea surface temperature, lower troposphere temperature, forecast

\section{INTRODUCTION}

It is well known that solar radiation is mainly absorbed by the surface of the earth and not by the "transparent" atmosphere. The oceans, which are in contact with the atmosphere for about $3 / 4$ of its lower boundaries, on the one hand accumulate and store solar energy and on the other release it to the atmosphere as latent and sensible heat. This energy release contributes to the movement 
of the atmosphere and sustains the major features of the general circulation. The great differences of the two media in density and thermal capacity are responsible for the slow reactions of the oceans to outside perturbations. This ability of the ocean to "remember" past influences, coupled with its importance as an atmospheric energy source, suggests that oceanic "events" may be precursors of long-term, large-scale atmospheric "events" (Barnett, 1978). Many researchers have attempted to use sea surface temperature (SST) patterns as a tool in long-range forecasting. Namias (1973), for example, utilizing seasonal SST and 1000-700 hPa thickness data, obtained contemporaneous correlations between the two variables south of the Aleutian low, in all seasons. $\mathrm{He}$ also argued that there is a suggestion of correspondence between winter and the subsequent spring. The recent years, however, it has been argued that air temperature (AT) may drive SST, even in large oceans (Cayan, 1992).

The purpose of this paper is a further research on the relation between lower Troposphere and sea surface temperature over the northern hemisphere and an investigation on the possibility of forecasting one from the other by using multivariate statistical methods.

\section{DATA AND METHOD}

Our data base consists of mean monthly values at grid points spaced by $5^{\circ}$ in latitude and $10^{\circ}$ in longitude for the 1000-500 hPa thickness (equivalent to lower troposphere AT) and by $5^{\circ}$ in latitude and $5^{\circ}$ in longitude for SST. Although SST data were available from the end of last century, the study had to be carried out for a much shorter period, for two reasons. First, because 1000-500 hPa thickness data do not exist for the pre-war period and second, because until 1966 there is a severe lack of data in most part of the Pacific Ocean. As this work focuses on investigating a possible monthly temperature forecast, a common period for both parameters is necessary. Therefore we had either to exclude the Pacific Ocean or to confine the research in the 22-year period, 1967-1988. It was preferred the latter in order to be able to detect possible connections of the very sensitive to El Niño events Pacific Ocean temperatures with the ones in other places of the Earth. Although the investigated period is not very long, it has the advantage that it stops before the intense global warming of the last 15 years, which maybe would affect the SST - AT relation because of the different inertia of the two media. The grid points used in 1000-500 hPa thickness are 419 , starting from $20^{\circ} \mathrm{N}$ (in lower latitudes the missing data are too many), while in SST they are 511 , starting from $7.5^{\circ} \mathrm{N}$ (very high latitudes where, in winter, sea is frozen were excluded). All data were kindly provided by the U.K. Meteorological Office. In the above specified understudy period and fields the encountered missing values were less than $0.5 \%$ and they were filled in using spatial and temporal interpolation. Since the total number of grid points is very large, a direct comparison of each of the SST time series with each of the 1000-500 hPa thickness time series, on the one hand is a laborious process and on the other hand encloses the threat of biased results due to possible undetected errors in the huge set of data. Furthermore, the presentation of the results will be very difficult especially if the study is done separately for each season. In cases like this the initial variables are reduced using multivariate statistical methods. In this study Factor Analysis will be used (see e.g. Jolliffe, 1986; Manly, 1986; Rummel, 1970).

Factor Analysis is based on the idea to describe a set of $p$ correlated variables, $T_{1}, T_{2}, \ldots, T_{p}$ in terms of a smaller number of uncorrelated indices or factors and hence clarify the relationship between variables. Each of the $p$ initial variables can be expressed as a linear function of $m(m<p)$ hypothetical orthogonal factors, i.e. $T_{i}=a_{i 1} F_{1}+a_{i 2} F_{2}+\ldots+a_{i m} F_{m}$, where $F_{j}$, $\mathrm{j}=1, \ldots, \mathrm{m}$, are the factors and $a_{i j}$ are the loadings. The initial variables are normalized, and thus each loading indicates the correlation coefficient between each variable $T_{i}$ and the factor $F_{j}$.

A subjective stage of this objective method is the decision for the number, $m$, of the retained factors. Many criteria have been proposed (Jolliffe, 1986; Overland and Preisendorfer, 1982; Rogers, 1990) but as some are stringent and some others are loose (Thurston and Spengler, 1985), they hardly indicate the same number of factors. In this respect, Jolliffe (1993) states "...different objectives for an analysis may lead to different rule being appropriate".

Another vital stage in Factor Analysis is the socalled rotation of the axes (factors). With this process, new factors, with different variances, are created (the total variance is unaffected) but the 
discrimination among the loadings is better and thus the interpretation of the results is easier. Furthermore, the rotation has been found to overcome certain characteristics of the unrotated solutions (dependence on the domain, subdomain stability, sampling errors, etc), which obscure the isolation of the individual modes of variation (Richman, 1986).

In this study the analysis is performed two times: for the winter and for the summer. But as we deal with the whole hemisphere and with two parameters (sea, air) it would be an oversimplification to use as "winter" and "summer" the conventional seasons, i.e. DJF and JJA respectively. Since in previous works of the authors on $1000-500 \mathrm{hPa}$ thickness and sea surface atmospheric pressure (Bartzokas and Metaxas, 1993; Metaxas and Bartzokas, 1994) it was found that more factors were necessary in summer than in winter, it was decided to carry out experimental factor analyses for every month in order to decide about the months which must be included in each "season". Although an analysis applied to a matrix of 22 rows (years)x419 columns (grid points) (22x511 for SST) is not an ideal one, the rough number of the groupings of the grid points clearly showed that March "behaves" similarly to the conventional winter months and September to the summer ones, in accordance to common oceanographic experience concerning SST inertia. Hence, in this work, "winter" consists of December, January, February and March (starting with December 1966) and "summer" of June, July, August and September.

In Factor Analysis, the maximum number of factors retained for rotation cannot exceed the smaller of the two dimensions of the initial data matrix. This means that if in the present study more than 22 factors are necessary, the analysis will not be performed properly. Therefore, the monthly values were not averaged to mean seasonal ones but all the individual monthly values were used, in order to increase the number of cases. Hence, matrices of $88 \times 419$ and $88 \times 511$ were formed for both seasons, which, as it will be seen in the next paragraph, are acceptable. But by forming longer time series consisting of all the individual months we possibly introduce a 4-month seasonal variation, which in many places of the earth may be strong enough obscuring others. The problem of whether such a variation must be subtracted or not, was also solved with experimental analyses. All the criteria for the optimum number of factors, showed that by keeping the seasonal variation in the time series the number of important factors (high variance and loadings), for both SST and thickness is limited to few only, which is unacceptable for the whole northern hemisphere. Hence, the time series were deseasonalized by subtracting 22-year means for each month of the year.

In order to decide about the optimum number of retained and rotated factors, we examined most of the criteria (Guttman, Scree, Lev, Monte Carlo technique (MCT) etc.) but, as it was expected, none appeared clearly as the ideal one. For instance, "Guttman criterion" (Jolliffe, 1986) for thickness (summer) indicates 51 factors but about half of them are unimportant inasmuch as their groupings appear very weak (few grid points, highest loading below 0.60). We note that in some works, it is possible to "guess" the optimum number of factors, especially when we know the physical mechanisms of their formation, but in this one the large number of variables does not allow such a guess. Therefore by selecting a criterion arbitrarily there would be the danger either of "underfactoring" (blending of discrete patterns, "forced" teleconnections, large areas unclassified) or "overfactoring" (very small unimportant groups, split of teleconnected areas). Hence, we decided to proceed step by step, carrying out many experimental analyses with various numbers of factors. The idea was to take into account the number of factors when the introduction of a few more did not cause a change in the grouping of the grid points. With this methodology it was found that, at the beginning, an increase of the number of factors causes also an increase in the number of groupings but later the number of groupings lags behind the number of factors with increasing difference. Apart from the selection of the optimum number of factors, another outstanding by-product of this methodology was the assessment of the various criteria. It was revealed that our results were very close to the ones given by MCT (Overland and Preisendorfer, 1982), which we eventually applied in this work. This criterion is designed to determine whether the factors' eigenvalues for a geophysical data set can be distinguished from those drawn at random. It keeps those factors that have eigenvalues exceeding $95 \%$ of the corresponding 
eigenvalues found by using random data. Finally, for the rotation of the axes the Orthogonal Varimax Rotation has been chosen, which keeps the factors uncorrelated.

\section{THE RESULTS OF FACTOR ANALYSIS}

The results of the 4 analyses, for SST and Thickness, for winter and summer are presented in Figures 1-4. The grid points depending on each factor are surrounded by the 0.60 loading isopleth, since tests have shown (Metaxas and Bartzokas, 1994) that the 0.60 isopleths of neighbouring factors usually do not cross over. The 0.80 loading isopleths have been also drawn. In this way, we define subareas inside which the variability of the under study parameter is almost identical with the one of the corresponding factor. In some cases two or more not neighbouring groups of grid points depend on the same factor; these are cases of teleconnection and they are marked with a straight line.

We note that apart from the two seasonal analyses, the annual one was also carried out, using $264 \times 419$ and $264 \times 511$ matrices. In general, the results for the "year" display mixed features of summer and of winter and therefore they are not presented.

The most important features of each of the seasonal pattern will be described in the following.

\section{Winter (DJFM)}

For winter, MCT has indicated 13 factors for SST (Fig. 1) and 16 for Thickness (Fig. 2), explaining $65 \%$ and $79 \%$ of the total variance respectively. The percentage for the SST analysis is lower, obviously due to the separation of the waters of the oceans by the continents, which is not the case for the air.

The most important findings of the winter analyses are two teleconnections, in both SST and Thickness. The first one is a sea-saw phenomenon (opposite loadings) between central Pacific (around $40^{\circ}$ ) and northeast Pacific (West Canada). Both in the sea (factor 1) and in the lower troposphere (factor 5) there is a contrast in temperature variation between these two areas. This see-saw corresponds exactly to Pacific North American Oscillation (PNA) revealed for surface pressure and for $500 \mathrm{hPa}$ geopotential height by Wallace and Gutzler (1981), considered to be related to equatorial and middle latitude SST anomalies (Horel and Wallace, 1981). Also,

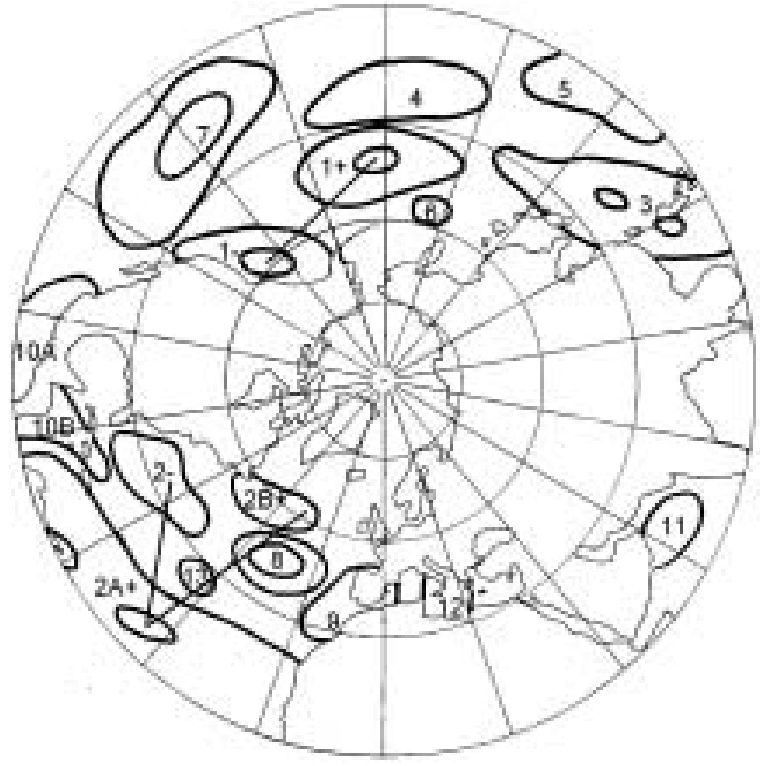

Figure 1. The subareas formed according to the rotated factor loadings, for winter SST. The curves drawn are the 0.60 and 0.80 loading isopleths. The numbers plotted are the factor number. Teleconnections are indicated with straight lines.

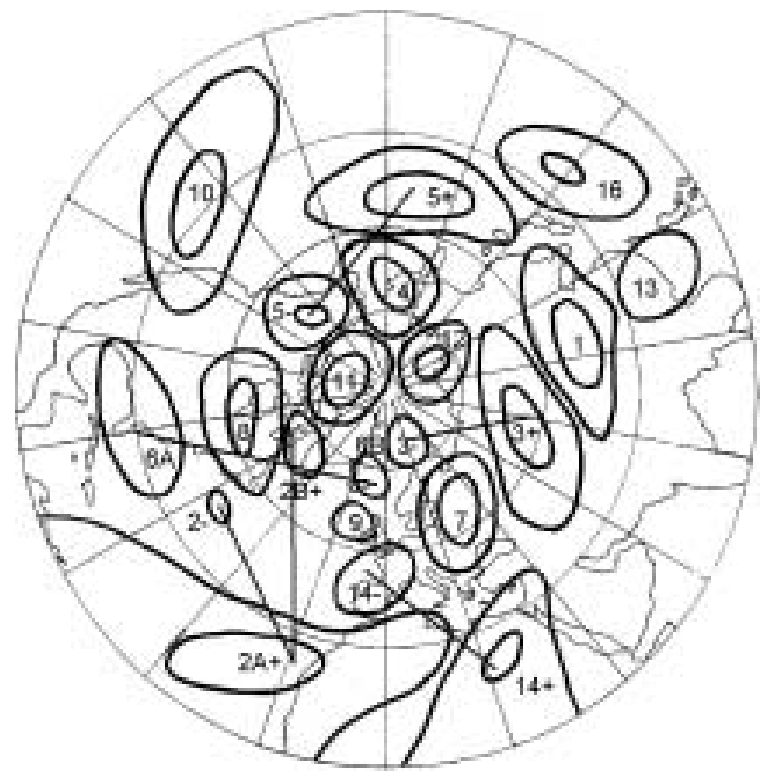

Figure 2. As in Figure 1, but for winter AT. 


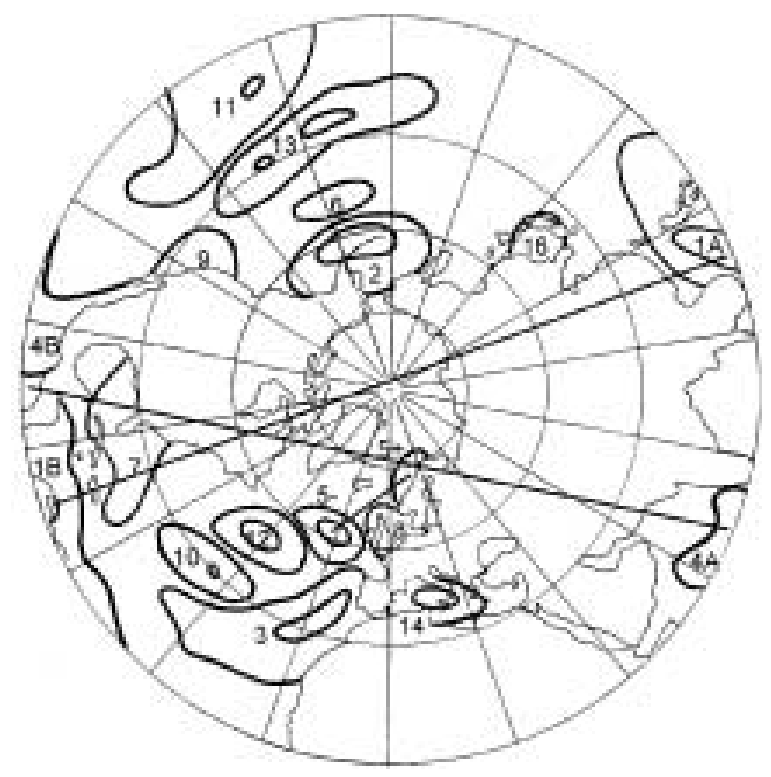

Figure 3. As in Figure 1, but for summer SST.

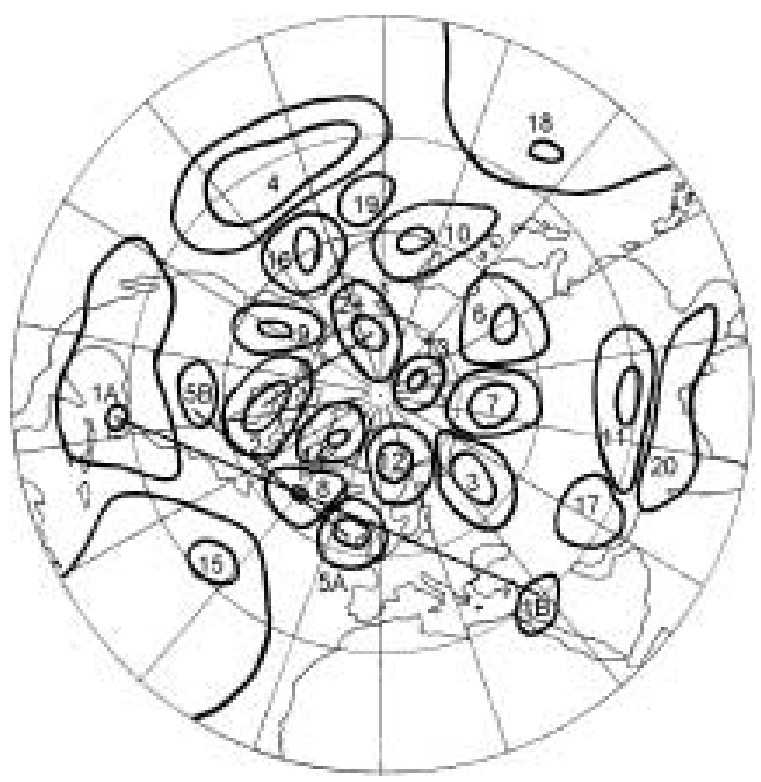

Figure 4. As in Figure 1, but for summer AT. the SST difference between the central Pacific warm current and the Californian cold current, as well as the temperature difference between the warm sea and the cold land of NW America must be related to this see-saw. The second teleconnection is an unusual triple one, among low latitudes C-E Atlantic, W Atlantic and N Atlantic; the second area being connected negatively to the others (factor 2, in both analyses). The grouping of the low latitude grid points could be attributed to the easterly Trade Winds and the covariability with the other areas must be due to North Atlantic Oscillation (NAO) (Wallace and Gutzler, 1981; Barnston and Livezey, 1987; Rogers, 1990, World Meteorological Organization, 1998). Positive NAO index values are associated with stronger cold air advection from the north at $2 \mathrm{~A}+$ and $2 \mathrm{~B}+$ areas as well as with stronger Labrador and Canaries islands currents (cold). At the same time, warm southerly air masses are advected at the 2- area along with a stronger Gulf Stream (warm). The opposite situation is valid during periods of negative NAO index values. We note that the position of the three groups is not precisely the same in both analyses but on the other hand such a unique case cannot be just a mathematical product without any physical meaning.

In Thickness, three more teleconnections were revealed. The first one is a see-saw phenomenon between W Asia (factor 3+) and the Norwegian sea (factor 3-), found by other researchers as well (Painting, 1977; Eriksson and Alexandersson, 1990; Bartzokas and Metaxas, 1993; Lolis and Bartzokas, 2001) and recently named as North Sea-Caspian Pattern (NCP) (Kutiel and Benaroch, 2002). The second one is a sea-saw phenomenon too, between W Europe (factor 14-) and SE Mediterranean - NE Africa (factor 14+), also found by other researchers (Metaxas, 1976; Bartzokas and Metaxas, 1993) and attributed to the position and persistence of a blocking anticyclone over Europe and the third one is a weak teleconnection between the Gulf of Mexico (factor 6A) and Iceland (factor 6B).

In SST there is one more teleconnection between the Caribbean Sea (factor 10B) and the low latitude E Pacific (factor 10A). These two seas are separated by Central America and therefore their temperature covariability surprises. However, in cases of weak sea currents their temperatures must show a common variation as they are both 
affected by the same air masses. The other SST factors appear as results either of sea currents (e.g. factor 3 - Curo Sivo) or of closed seas (e.g. factor 12 - Mediterranean, factor 11 - Arabian sea).

\section{Summer (JJAS)}

In summer, 16 factors have been retained for SST explaining $65 \%$ of the total variance and 20 for Thickness $(76 \%)$. The subareas defined can be seen in Figures 3 and 4 respectively. The first conclusion drawn is that more factors are necessary in summer than in winter, in agreement with the other aforementioned large scale studies.

In SST there are three teleconnections. Two of them are very impressive as they connect areas with $180^{\circ}$ longitude difference. The first connects low latitudes, central and west Atlantic (factor 1B), with west Pacific (South China Sea) (factor 1A) and the second, which is weaker, the Arabian sea (factor 4A - highest loading 0.62) with low latitudes east Pacific (factor 4B - highest loading 0.82). What is in common between the areas of the first teleconnection is that both of them are affected by Tropical Cyclones/Hurricanes, which may cause mutual features to sea surface. However such an argument cannot explain the finding since for a teleconnection the frequency the Cyclones should be the same in both Oceans, which is not valid. No other explanation can be offered. The second teleconnection is a rather marginal one, which would be split if the number of the retained factors were greater. The third teleconnection is a see-saw phenomenon between E Atlantic (factor 5-) and the Norwegian sea (factor 5+) which may be related to the depressions tacks which in summer are displaced in higher latitudes, frequently passing between these two subareas. The Icelandic low, being located between these two areas, must be responsible for the opposite sign. We note that this teleconnection is the only one, of those revealed in the seasonal analyses, that was also found in the analysis for the "year" (results not presented), a fact that underlines the strength of this see-saw. Apart from the teleconnections, another worth mentioning feature of the summer SST pattern is the appearance of the closed seas factors. In summer, a sea not affected much by currents is warmed up faster than the other seas, forming its own characteristics. This is the case of the Mediterranean Sea (factor 14), the North Sea (factor 8), the Gulf of Mexico (factor 7), and the Sea of Japan (factor 16).
In Thickness there are two main teleconnections. The first is between the British Isles (factor 5A) and the area of the Great American Lakes (factor 5B) and it might be attributed to the effect of two ridges over these areas (Rossby waves). We note that NE America and NW Europe have been found connected through various parameters. E.g. Ratcliffe and Murray (1970) found a connection between SST off Newfoundland and pressure patterns for the following month in $\mathrm{W}$ Europe. The second teleconnection is a see-saw phenomenon between Hudson Bay (factor 2-) and the Bering sea (factor 2+). The distance between these two areas is about half of the distance between the above connected areas (5A-5B) which means that a stationary ridge (or a trough) between them could be responsible for the contrast of their temperatures. In any case, the significance of factor 2 (about 15 grid points with absolute loadings above 0.60 in each subarea and high central loadings, -0.86 and 0.83 ), strongly indicates that this finding cannot be just an artifact of the calculations. There is a third teleconnection in Thickness, a weak one between a large subarea over Mexico/USA (factor 1A) and a small one over northern Arabia (factor 1B). At first its validity was considered doubtful but, as it will be shown in the next section, it does exist. Other noticeable factors of figure 4 are: (i) the 3 factors over Siberia $(3,6,7)$ appearing as a multidivision of the winter Siberian factor (3) due, evidently, to the disappearance of the thermal winter anticyclone, (ii) the strong Atlantic factor (15), generated by the subtropical (Azores) anticyclone, (iii) the Monsoonal factor (20) over India, (iv) the Himalayas plateau factor (11), (v) the Greenland plateau factor (14), etc.

In general, although it was not possible to give a physical interpretation for the covariability of temperature in all grid groupings, the high correlation of each factor with temperature time series at concentrated grids does indicate that the nature of the underlying surface and the prevailing circulation are the primary causes of these groupings.

\section{CONNECTION BETWEEN SST AND 1000-500 $\mathrm{hPa}$ THICKNESS}

In this paragraph possible covariabilities between sea surface and lower troposphere temperatures over the northern hemisphere are examined. The reduction of the number of variables achieved by 
Table 1. The highest correlation coefficients between lower troposphere and sea surface temperature, according to Factor Analysis categorization, for winter

\begin{tabular}{|clclc|}
\hline \multicolumn{2}{c}{ Thickness subareas } & & SST subareas & r \\
\hline $5+$ & C Pacific & $1+$ & C Pacific & 0.70 \\
$5+$ & C Pacific & $1-$ & NE Pacific & -0.69 \\
$2+$ A & low latitude Atlantic & $2+$ A & low latitude Atlantic & 0.59 \\
$5-$ & NE Pacific & $1-$ & NE Pacific & 0.57 \\
$5-$ & NE Pacific & $1+$ & C Pacific & -0.54 \\
$2+$ A & low latitude Atlantic & $2-$ & W Atlantic & -0.52 \\
16 & W Pacific & 3 & W Pacific & 0.50 \\
13 & South China & 3 & W Pacific & 0.48 \\
\hline
\end{tabular}

Table 2. As in Table 1 but for summer

\begin{tabular}{|clclc|}
\hline & Thickness subareas & & SST subareas & r \\
\hline 1A & Gulf of Mexico & 7 & Gulf of Mexico & 0.57 \\
$1 \mathrm{~A}$ & Gulf of Mexico & $1 \mathrm{~B}$ & low latitude Atlantic & 0.53 \\
12 & Norwegian sea & $5+$ & Norwegian sea & 0.50 \\
$5 \mathrm{~A}$ & E Atlantic & $5-$ & E Atlantic & 0.49 \\
4 & C Pacific & 13 & C Pacific & 0.45 \\
16 & NE Pacific & 6 & N Pacific & 0.43 \\
15 & low \& mid. lat. Atlantic & $1 \mathrm{~B}$ & low latitude Atlantic & 0.42 \\
\hline
\end{tabular}

FA allows an easier and safer approach, as causes of covariability definitely affect broad fields and not individual stations or grid points. MCT, being a strict criterion, on the one hand gave subareas statistically significant, but on the other limited the percentage of the total variance explained by the retained factors to about $65 \%$ and $80 \%$, for SST and Thickness respectively. Moreover, the majority of the highest factor loadings, around the centres of the subareas defined, are between 0.75 and 0.85 (absolute values) and they hardly exceed 0.90 . This means that if the factor scores time series are used as representative of the temperature time series of the subareas, the results will be biased. Thus, in this work the Factor Analysis groupings (Figs. 1-4) are considered as an objective guide and instead of the frequently used factor scores the actual temperatures are utilized. For each subarea, the average temperature time series of the grid points enclosed by the 0.60 loading isopleth is estimated. The new time series were also deseasonalized and standardized (unit variance, zero mean) in accordance with the above computed factor scores.

A possible covariability between SST and Thickness is investigated by estimating the correlation coefficients between all possible SSTThickness pairs of the average time series of the subareas. This is done twice, for winter and for summer. The highest correlation coefficients found are presented in Tables 1 and 2.

From the above Tables, two main conclusions can be drawn. First, the highest correlation coefficients appear between subareas of the two media located one over/under the other and second, the subareas involved in most of pairs are the large ones. This means that in order to have the same temperature variability from sea surface up to a height of about $5,500 \mathrm{~m}$, the main characteristics of the sea and/or the air must be well established, which also implies a substantial spatial extension. In general, all the revealed correlations proved that lower troposphere and sea surface temperature fluctuations are definitely related but in no 
Table 3. The highest correlation coefficients as they appear in the correlation matrix of the SST or the Thickness subareas

\begin{tabular}{|cc|c|c|c|}
\hline \multicolumn{2}{|c|}{ Subareas } & SST/Thickness & Season & r \\
\hline $1+$ & $1-$ & SST & winter & -0.81 \\
$10 \mathrm{~A}$ & $10 \mathrm{~B}$ & SST & winter & 0.74 \\
$5+$ & $5-$ & Thickness & winter & -0.72 \\
$2+\mathrm{A}$ & $2+\mathrm{B}$ & SST & winter & 0.70 \\
$2+\mathrm{A}$ & $2-$ & SST & winter & -0.70 \\
$1 \mathrm{~A}$ & $1 \mathrm{~B}$ & SST & summer & 0.67 \\
$1 \mathrm{~A}$ & $1 \mathrm{~B}$ & Thickness & summer & 0.66 \\
$2+\mathrm{B}$ & $2-$ & SST & winter & -0.65 \\
$5+$ & $5-$ & SST & summer & -0.64 \\
$2+$ & $2-$ & Thickness & summer & -0.63 \\
\hline
\end{tabular}

case one explains more than $49 \%$ of the variance of the other $(r=0.70)$. Correlation coefficients between subareas not located one over/under the other, mostly are not statistically significant (the 95\% confidence level limit is: $r=0.22$ ) and in rare cases that they are significant, they are much lower than 0.40 and they have not been included in the Tables. It is also noted that the correlation coefficients between the factor scores were also estimated as a test, but, as was expected, they were found lower than the ones of the above Tables. All the coefficients, but one, were lower than 0.50 , which is another indication that the research of an air-sea connection via the factor scores would yield biased and weaker results.

Another by-product of the estimation of the above coefficients is an indirect assessment of the teleconnections revealed by the Factor Analysis. E.g. the four couples appearing in Table 1 between factor 5 of thickness and factor 1 of SST unquestionably verify the existence of the teleconnection between $\mathrm{C}$ and NE Pacific (PNA) in winter, as in SST as in Thickness. Apart from this indirect verification, a further assessment of the aforementioned teleconnections by calculating air-air and sea-sea correlation matrices was attempted. The highest coefficients $(r>0.60)$ are presented in Table 3 .

All the connections appearing in Table 3 have been already revealed by the Factor Analysis. This similarity confirms that the selection of MCT was right. It is also verified that MCT gives real teleconnections and not "forced" pairs due to underfactoring. Moreover, teleconnections for the validity of which there were some doubts, e.g. the summer one in thickness between the Gulf of Mexico and the Arabian desert (factor 1A-1B), are now proved to be also real.

\section{FORECAST}

The coefficients presented in Tables 1 and 2 clearly underline the association between sea surface and lower troposphere temperature. However the correlation of these two parameters is not as simple as it is described by a first order regression. An accurate correlation can be more complex, connecting different types of data and not synchronous. In this study temperature only is utilized and in this paragraph a possible dependence of AT from SST of previous months is sought and vice versa.

Using the average temperature time series of the previous paragraph, it is attempted to forecast one parameter from the other using time lags up to 3 months. We note that as the time series consist of 22 successions of four consecutive months, an introduction of a time lag of one month would effect some inadequate pairs of data connecting values found 10 months apart. E.g. with a time lag of one month in summer, when in one time series the temperature change from August to September is examined, in the other time series the temperature change from September to next June would appear, which is not acceptable. In order to avoid this problem, the four consecutive months were reduced to three and 22 successions of JJA were compared with 22 successions of JAS. In this way a time lag of one month inevitably reduces the 
Table 4. Forecasting Thickness and SST

Winter: Forecasting Thickness (JFM) from SST (DJF)

\begin{tabular}{cl|cl|c|c|c}
\hline \multicolumn{2}{c|}{ Thickness subareas } & \multicolumn{2}{|c|}{ SST subareas } & lag & r & \multicolumn{1}{c}{$\Delta$} \\
\hline $2+\mathrm{A}$ & Atlantic & 13 & Atlantic & 2 & 0.56 & 0.23 \\
$2+\mathrm{B}$ & NW Atlantic & 13 & Atlantic & 2 & 0.52 & 0.11 \\
14 & SE Mediterranean & 8 & E Atlantic & 2 & -0.50 & -0.24 \\
$5+$ & C Pacific & 7 & E Pacific & 2 & -0.54 & -0.13 \\
$5-$ & NE Pacific & $10 \mathrm{~A}$ & low latitude E Pacific & 3 & 0.57 & 0.43 \\
$5-$ & NE Pacific & $10 \mathrm{~B}$ & Caribbean sea & 3 & 0.58 & 0.54 \\
\hline
\end{tabular}

Winter: Forecasting SST (JFM) from Thickness (DJF)

\begin{tabular}{|c|c|c|c|c|c|c|}
\hline \multicolumn{2}{|c|}{ Thickness subareas } & \multicolumn{2}{|c|}{ SST subareas } & \multirow{2}{*}{$\begin{array}{c}\text { lag } \\
1\end{array}$} & \multirow{2}{*}{$\begin{array}{c}\mathbf{r} \\
0.78\end{array}$} & \multirow{2}{*}{$\begin{array}{r}\Delta \mathbf{r} \\
0.08\end{array}$} \\
\hline $5+$ & C Pacific & $1+$ & C Pacific & & & \\
\hline $5+$ & C Pacific & $1-$ & NE Pacific & 1 & -0.76 & -0.07 \\
\hline $5-$ & NE Pacific & $1+$ & C Pacific & 1 & -0.62 & -0.08 \\
\hline $5-$ & NE Pacific & $1-$ & NE Pacific & 1 & 0.61 & 0.04 \\
\hline 13 & South China & 3 & W Pacific & 1 & 0.54 & 0.06 \\
\hline $5+$ & C Pacific & $1+$ & C Pacific & 2 & 0.75 & 0.05 \\
\hline $5-$ & NE Pacific & $1+$ & C Pacific & 2 & -0.62 & -0.08 \\
\hline $5+$ & C Pacific & $1+$ & C Pacific & 3 & 0.74 & 0.04 \\
\hline
\end{tabular}

\begin{tabular}{|c|c|c|c|c|c|c|}
\hline \multicolumn{7}{|c|}{ Summer: Forecasting Thickness (JAS) from SST (JJA) } \\
\hline \multicolumn{2}{|c|}{ Thickness subareas } & \multicolumn{2}{|c|}{ SST subareas } & \multirow{2}{*}{$\frac{\text { lag }}{1}$} & \multirow{2}{*}{$\begin{array}{c}\mathbf{r} \\
0.60\end{array}$} & \multirow{2}{*}{$\frac{\Delta \mathbf{r}}{0.07}$} \\
\hline $1 \mathrm{~A}$ & Gulf of Mexico & 1B & low latitude Atlantic & & & \\
\hline 1B & Arabia & 7 & Gulf of Mexico & 2 & 0.53 & 0.20 \\
\hline 13 & Arctic Siberia & 6 & N Pacific & 3 & 0.60 & 0.38 \\
\hline $2-$ & Hudson Bay & $5+$ & Norwegian sea & 3 & -0.60 & -0.52 \\
\hline \multicolumn{7}{|c|}{ Summer: Forecasting SST (JAS) from Thickness (JJA) } \\
\hline \multicolumn{2}{|c|}{ Thickness subareas } & \multicolumn{2}{|c|}{ SST subareas } & lag & $\mathbf{r}$ & $\Delta \mathbf{r}$ \\
\hline $1 \mathrm{~A}$ & Gulf of Mexico & 7 & Gulf of Mexico & 1 & 0.58 & 0.01 \\
\hline $1 \mathrm{~A}$ & Gulf of Mexico & $1 \mathrm{~B}$ & low latitude Atlantic & 1 & 0.55 & 0.02 \\
\hline 12 & Norwegian sea & $5+$ & Norwegian sea & 1 & 0.52 & 0.02 \\
\hline $1 \mathrm{~A}$ & Gulf of Mexico & $1 \mathrm{~B}$ & low latitude Atlantic & 2 & 0.57 & 0.04 \\
\hline 14 & Greenland & 14 & Mediterranean sea & 3 & 0.56 & 0.29 \\
\hline
\end{tabular}

number of data from 88 to 66 , a time lag of two months to 44 and a time lag of three to 22 .

The new correlation coefficients, in general, are lower than the ones without time lag and are reduced as time lag increases. It appears then that forecasting Thickness from SST, or vice versa, is not possible. Nevertheless there are places where the coefficients appear increasing (absolutely) with lag. These cases are presented in Table 4, provided that the new coefficient is absolutely higher than 0.50 , and they will be further examined.

The highest coefficient seen in Table 4 is the one between the C Pacific areas 1+ (SST) and 5+ (Thickness) for winter $(r=0.78)$. These two areas are also correlated with the highest coefficient $(\mathrm{r}=0.70)$ without any time lag (Table 1$)$. In general, high coefficients in Table 4 connect areas, which are also highly correlated without time lag. Therefore, we tested the statistical significance of 
the differences (Spiegel, 1961) given in column $\Delta \mathrm{r}$. It was found that none of them is statistically significant at $95 \%$ confidence level. For instance the 0.08 increase of the above mentioned highest coefficient is significant at $72 \%$ confidence level only. It seems then that the high values encountered are due to persistence rather than to other mechanisms. The high differences appearing in some cases in lag 3 are not significant either since, as it was mentioned above, the time series are shortened. Another conclusion drawn from Table 4 is that in winter coefficients are higher than in summer. Also, it is seen that in winter it is easier to forecast SST from air temperature than air temperature from SST. E.g. in Table $4 b$ there appear all the couples between the subareas $5 \pm$ and $1 \pm$, which is not the case for Table $4 \mathrm{a}$, since coefficients were found lower than the corresponding ones of Table 1. This, surprises at first as many researchers in the past have tried to forecast air temperature based on SST persistence. However, the attempts, which gave evidences that anomalous SST has an impact on weather regime of the atmosphere, were based on timescales approaching a season (see e.g. Palmer and Anderson, 1993) while the present work deals with monthly values. Moreover we note that sensible heat, which partially regulates air temperature, is mainly controlled by wind speed and less by SST (Cayan, 1992). Also, we remind that this research deals with the whole lower Troposphere having a "thickness" of about $5,500 \mathrm{~m}$.

Finally, another attempt was made to forecast SST from Thickness (or Thickness from SST) examining possible connection of summer values of the one parameter and winter values of the other and vice versa. From all the coefficients calculated one only exceeds 0.50 . It is the one connecting $(\mathrm{r}=0.52)$ winter thickness of low latitude Atlantic (factor 2+A, Fig. 2) and with next summer's SST in the same area (factor 1B, Fig. 3). The other coefficients, although are relatively low confirm that it is easier to forecast SST from Thickness (where it is possible) than Thickness from SST as these of the first case are higher than those of the second.

The coefficients calculated in this last paragraph, although were not found significantly higher than the ones of the previous paragraph, do indicate that in some places of the Earth there is a sub- stantial time lag connection between SST and Thickness either due to persistence or to some other mechanism.

\section{CONCLUSIONS}

In this paper the covariability and the connection of SST and 1000-500 hPa thickness over the northern hemisphere were investigated.

In the first part, initially the grid points were grouped objectively by using the method of Factor Analysis. In this way, on the one hand it was achieved a reduction of the numerous original variables, in order to be handled easier, and on the other hand the existing spatial covariances and teleconnections were revealed. Moreover it was proved that the "Monte Carlo" technique is the best rule for retaining the optimum number of factors. The strongest teleconnection revealed is the PNA, a winter see-saw between $\mathrm{C}$ and $\mathrm{NE}$ Pacific dominating as in the SST as in the Thickness patterns. Another striking teleconnection found is a triple one in the Atlantic, also appearing in winter in both parameters, attributed to NAO. In general, it can be argued that the groupings appear as consequences of the general circulation, the sea currents regime and, for Thickness, of the nature of the underlying surface.

In the second part, the regions where SST and Thickness time series are correlated were specified. Correlation coefficients are as high as 0.70 , the highest found over the $\mathrm{C}$ and NE Pacific Ocean. Generally, well established SST and Thickness subareas, located one over the other, are highly correlated.

Finally, introducing time lags, the possibility of forecasting one of the parameters from the other was investigated. It was found that there are areas where the correlation coefficients are not reduced as lag increases but they increase slightly, though not significantly at $95 \%$ confidence level. Such areas are again the ones of the Pacific Ocean. It was also found that the forecast is better when SST is forecasted from Thickness, probably due to the monthly time scale used and the large vertical extend of the lower Troposphere. Although an acceptable forecast must be based on the highest possible correlation, which, obviously, cannot be simple linear but of higher order and/or multiple, the findings of this work must be taken in to account in a further research on this field. 


\section{REFERENCES}

Barnett, T. P. (1978), The role of the oceans in the global climate system. Climatic Change, (ed. J. Gribbin). Cambridge, Cambridge University Press, 280 pp.

Barnston, M. P. and Livezey, R. E. (1987), Classification, seasonality and persistence of low frequency atmospheric circulation patterns, Monthly Weather Review, 115, 1083-1126.

Bartzokas, A. and Metaxas, D. A. (1993), Covariability and climatic changes of the lower-Troposphere temperatures over the northern hemisphere, Il Nuovo Cimento, 16C, 359-373.

Cayan, D. R. (1992), Latent and Sensible Heat Flux Anomalies over the Northern Oceans: Driving the Sea Surface Temperature, Journal of Physical Oceanography, 22, 859-881.

Eriksson, B. and Alexandersson, H. (1990), Our Changing Climate, Agricultural and Forest Meteorology, 50, 55-64.

Horel, J. D. and Wallace, J. M. (1981), Planetary-scale atmospheric phenomena associated with the Southern Oscillation, Monthly Weather Review, 109, 813-829.

Jolliffe, I. T. (1986), Principal Component Analysis, New York, Springer-Verlang, 271 pp.

Jolliffe, I. T. (1993), Principal component analysis: A beginner's guide - II. Pitfalls, myths and extensions, Weather, 48, 246-253.

Kutiel, H. and Benaroch, Y. (2002), North Sea-Caspian Pattern (NCP) - an upper level atmospheric teleconnection affecting the Eastern Mediterranean: Identification and definition, Theoretical and Applied Climatology, 71, 17-28.

Lolis, C. J. and Bartzokas, A. (2001), Winter temperature covariances in the middle and the lower troposphere over Europe and the North Atlantic Ocean, International Journal of Climatology, 21, 679-696.

Manly, B. F. J. (1986), Multivariate statistical methods: A primer. London, Chapman \& Hall, 159 pp.

Metaxas, D. A. (1976), Monthly and Seasonal Temperature Correlation Between C, England and Athens. Univ. of Ioannina Technical Report, No 64, 8 pp.

Metaxas, D. A. and Bartzokas, A. (1994), Pressure Covariability over the Atlantic, Europe and N. Africa. Application: Centers of Action for Temperature, Winter Precipitation and Summer Winds in Athens, Greece, Theoretical and Applied Climatology, 49, 9-18.

Namias, J. (1973), Thermal communication between the sea surface and the lower Troposphere, Journal of Physical Oceanography, 3, 373-378.

Overland, J. E. and Preisendorfer, R. W. (1982), A significant test for principal components applied to a cyclone climatology, Monthly Weather Review, 110, 1-4.

Palmer, T. N. and Anderson, D. L. T. (1993), Scientific assessment of the prospects for seasonal forecasting: a European perspective, European Centre for Medium-Range Weather Forecasts, Technical Report No. 70, Berkshire, England, 34 pp.

Painting, D. J. (1977), A Study of some Aspects of the Climate of the Northern Hemisphere in Recent Years, Meteorological Office, Scientific Paper No 35, HMSO, London, 25 pp.

Richman, M. B. (1986), Review article. Rotation of principal components, Journal of Climatology, 6, 293-335.

Rogers, J. C. (1990), Patterns of low-frequency monthly sea level pressure variability (1899-1986) and associated wave cyclone frequencies, Journal of Climate, 3, 1364-1379.

Rummel, R. J. (1970), Applied Factor Analysis. Evanston IL: Northwestern Univ. Press, 617 pp.

Ratcliffe, R. A. S. and Murray, R. (1970), New lag associations between North Atlantic sea temperature and European pressure applied to long-range weather forecasting, Quarterly Journal of the Royal Meteorological Society, 96, 226-246.

Spiegel, M. R. (1961), Theory and Problems of Statistics. Schaum's Outline Series. London: McGraw-Hill Book Company, 360 pp.

Thurston, G. D. and Spengler, J. D. (1985), A multivariate assessment of meteorological influences on inhalable particle source impacts, Journal of Climate and Applied Meteorology, 24, 1245-1256.

Wallace, J. M. and Gutzler, D. S. (1981), Teleconnections in the Geopotential Height Field during the Northern Hemisphere Winter, Monthly Weather Review, 109, 784-812.

World Meteorological Organization (1998), The Global Climate System Review, Climate System Monitoring December 1993-May 1996, In: World Climate Data and Monitoring Programme, Nichols JM (ed.). WMO-No. 856. 